\title{
¿Qué hace un camino? Alteraciones infraestructurales en el Sur de Chile
}

\section{Cristóbal Bonelli}

- Universidad de Amsterdam / Amsterdam, Holanda

$\boldsymbol{\nabla}$ cristobalbonelli@gmail.com

\section{Marcelo González Gálvez}

- Pontificia Universidad Católica de Chile / Santiago, Chile

、magonzalezg@uc.cl

\section{RESUMEN}

En este artículo, intentamos dar cuenta de la transformación sociomaterial que ha gatillado la construcción de caminos en los mundos indígenas del sur de Chile. Inspirados inicialmente por la noción de "mente inmanente" batesoniana, intentamos comprender y conceptualizar las capacidades de los caminos para potenciar radicalmente la reconstitución de un mundo relacionalmente constituido, y que por tanto es de suyo contingente. A partir de nuestras exploraciones etnográficas, proponemos que el camino no posibilita la alteración simplemente porque promueve el contacto, la interconexión, y las relaciones interculturales, sino porque altera materialmente el mundo, promoviendo relaciones intersociomateriales determinadas infraestructuralmente. Finalmente, exponemos que la alteración material del mundo produce resultados inciertos, posibilitando incluso su propia destrucción. En este sentido, este trabajo discute etnográficamente el problema de la auto-determinación ontológica en términos infraestructurales. 
Consideremos un hombre que derriba un árbol con un hacha. Cada golpe del hacha es modificado o corregido, de acuerdo con la figura de la cara cortada del árbol que ha dejado el golpe anterior. Este proceso auto-correctivo (es decir, mental) es llevado a cabo por un sistema total, árbol-ojos-cerebro-músculos-hacha-golpe-árbol, y este sistema total es el que tiene características de mente inmanente. Más correctamente: tendríamos que formular el asunto como: (diferencias en el árbol)-(diferencias en la retina)-(diferencias en el cerebro)-(diferencias en los músculos)-(diferencias en el movimiento del hacha), etcétera. Lo que se transmite alrededor del circuito son transformaciones de diferencias. $Y$, como se señaló anteriormente, una diferencia que hace una diferencia es una idea o unidad de información. Pero este no es el modo en como el hombre-promedio de Occidente ve el evento de la secuencia del árbol que está siendo derribado. Él dice: "Yo corto el árbol" e incluso piensa que hay un agente delimitado, el "self", que realizó una acción intencionada sobre un objeto delimitado.

Gregory Bateson

Mi hermano mayor, Lorenzo... Él fue muy ambicioso, le copió mucho a los winka, todo lo que el winka tenía, él tenía que tenerlo... Y tenía recursos así que lo conseguía... Después que se abrió el camino hace unos 30 años a trás, él se empezó a weiweicar, a volverse loco, yo quiero esto, yo quiero lo otro... Él fue el primero que se compró una motosierra, y eso fue un error. Antes de eso no se conocía motosierra, nadie, una cuestión que se echaba andar y sonaba como un vehículo, impresionante... Y se compró una... Grueso error... Empezó a cortar los árboles sin medida, sin consecuencia. Disfrutaba cortando árboles... y fue una cuestión tan impactante, cortar robles grandes enteros que había, o por gusto cortar palos, y prácticamente no dejó árbol, sobre todo hualle... Y la gente empezó a tener motosierra, y a hí quedo la crema, empezaron a cortar palos sin medida, sin consecuencia, empezaron a llevar arriba las pinalerias, a cortarcuestiones pa' hacer puestos... Y eso fue transgredir la naturaleza, transgredir todo, porque antes nadie hablaba o gritaba arriba en la pinaleria, y llegar con una moto, según los antiguos, la gente anciana dice que esa cuestión espanta todo el newen, y sacan los ngen que están ahí en la naturaleza, se asustan, se arrancan, y ahí queda la crema. Ahí empezó el tema de la invasión de la naturaleza, nosotros mismos fuimos los culpables del tema, no hubo medida, y así estamos. La tierra no tiene fuerza, no tenemos fuerza como pewenche, no pensamos como pensaban nuestros abuelos, padres... Estamos locos... Hoy día estamos pensando en cosas... En la plata, no tengo trabajo, en comprar, una tele, un plasma, una camioneta, un auto, tener una casa de lujo, esa onda... Todas cosas que trajo el camino. 
¿Cómo entender la relación de un árbol con el hombre que lo corta? ¿Qué tipo de epistemología resulta más adecuada para pensar este vínculo? Intentando ilustrar pedagógicamente distintos modos de conceptualizar la relación organismo-ambiente, Gregory Bateson (1972) nos ofrece, en el primer epígrafe de este artículo, dos epistemo-lógicas para entender dicha relación. De un lado, una lógica dicotómica, que separa "de raíz" al sujeto que corta del objeto cortado; del otro, una "eco-lógica", que sitúa a los elementos de la descripción como pertenecientes a una cadena de diferencias conectadas inmanentemente.

En el segundo epígrafe, Francisco, nombre ficticio que hemos dado a una persona mapuche-pewenche del sur de Chile, describe una relación entre el árbol y quien lo corta a partir de la incorporación de la motosierra. A diferencia de la distinción realizada por Bateson, Francisco parece no distinguir tan clara y distintamente entre un "hombre occidental promedio" y un hombre "menos promedio" y "menos occidental"; para Francisco, su hermano es siempre su hermano, la misma persona, aun cuando sus prácticas se vean alteradas. Lo que sucede es que la incorporación material de la motosierra hace posible la aparición de nuevos modos de relación entre el árbol y quién lo corta. Es, en efecto, la tecnología material del winka, el otro paradigmático en el mundo mapuche' ' la que posibilita aunque no necesariamente determina la alteración de las prácticas relacionales que el hermano de Francisco establece con el árbol. De modo similar en que el bastón del ciego es considerado como una extensión de la visión de quien lo utiliza empleando otra analogía batesoniana, Francisco parece implicar que tanto hacha y motosierra son extensiones de su hermano. Pero, al ocurrir la sustitución de una por la otra, el hermano de Francisco "enloquece" (o weiweikea) y pasa a asemejarse al "hombre occidental promedio" imaginado por Bateson, esta vez, alterado por "todas [las] cosas que trajo el camino".

Lo que intentamos explorar en este artículo es el tipo de alteración sociomaterial que aparece gatillada por el camino. De manera casi experimental, nos interesa expandir el evento tecnológico específico que habría provocado el cambio percibido por Francisco tanto en su hermano como en otros, y analizar el metabolismo material que genera la introducción de esta infraestructura vial en los mundos indígenas. En otras palabras, exploraremos etnográficamente qué hace un camino, intentando dar cuenta de las alteraciones que produce respecto a lo que puede ser considerado o no, en última instancia, como "mundo material".

En una lógica cercana a la expuesta por ese "hombre occidental" referido por Bateson, un camino es usualmente comprendido como una infraestructura que transporta materiales y facilita el flujo y la interconexión de tecnologías y entidades diversas. Lo que intentaremos demostrar en este artículo, o al menos lo que creemos que nuestras etnografías ofrecen, es una reflexión menos obvia respecto a lo que un camino hace: el camino no solo transporta materiales, sino
1 El término winka provendría de la expresión "pu inka" ("los inka"), pero se utiliza indistintamente para referir a todos quienes, por distintas razones, son considerados no mapuche (españoles, chilenos, y otros extranjeros). Para una profundización sobre esta noción, véase González Gálvez (2016) 
que también produce tensiones, transforma y multiplica los mundos sociomateriales en que se introduce. Intentaremos describir cómo lo que a primera vista puede ser lisa y llanamente considerado como una conexión material entre mundos preexistentes, en realidad, implica procesos metabólicos sociomateriales muchos más complejos, inciertos e impredecibles.

Para la realización de esta reflexión, nos inspiramos en debates antropológicos recientes que han ubicado justamente al camino en el centro de las indagaciones etnográficas, conceptualizándolo como la infraestructura paradigmática del siglo XXI, en tanto facilita el desarrollo de la así llamada "sociedad de la información" y la realización de actividades extractivas fundamentales para las economías nacionales (Dalakoglou y Harvey, 2012). Entre otras cosas, estas aproximaciones han mostrado que los caminos no solo funcionan como conectores y desconectores (también ordenadores y potenciadores) de distintos objetos y sujetos, sino que además tienen la capacidad de transformar relaciones sociales y materiales, generando nuevos mundos (Dalakoglou y Harvey, 2012; Pedersen y Bunckenborg, 2012). En este sentido, creemos posible entender el camino no simplemente como un ente inerte que permite y potencia o incluso expresa la conexión, el intercambio y la interacción entre diferentes sujetos y objetos, sino que como una parte integral de un sistema relacionalmente constituido que, de hecho, por esto mismo, se reconfigura a partir de su integración. Luego, el camino no sería solamente una infraestructura que se monta sobre el paisaje, alterándolo como si fuese una suerte de adición al paisaje "allá fuera", sino que sería una parte constituyente de lo que Jensen (2015) denomina "infraestructuras ambientales": sistemas relacionales contingentes que generan articulaciones socionaturales y políticas inciertas e insospechadas.

Considerando esto, este artículo intenta dos apuestas que nos parecen fundamentales para aproximarnos a la infraestructura de los mundos vividos por distintos agentes, y que derivan estrictamente de nuestra propia aproximación etnográfica a estos mundos. La primera apuesta se relaciona con desestabilizar, una vez más, la distinción entre el mundo y su representación, o entre la infraestructura y la superestructura, para abrazar una aprehensión de la vida que se aproxime más adecuadamente a aquella que experimentamos etnográficamente y que, lejos de hacer estas distinciones dualistas, aplica prácticas consistentemente monistas (Henare, Holbraad y Wastell, 2007). Para esto, nos apoyamos en la noción de "infra-reflexibilidad" propuesta por Bruno Latour (1988), que intenta dar cuenta de un tipo de reflexividad inmanente propia de los ensamblajes infraestructurales, intentando, además, evitar a toda costa el desarrollo de metalenguages. Con este espíritu, nuestra infra-reflexión etnográfica intentará mantenerse al margen de aproximaciones que consideran, por un lado, los materiales infraestructurales como una mera expresión de estructuras sociales y 
políticas preexistentes, o por otro, como el determinante último de la vida social (Hennion y Grenier, 2000; Jensen, 2015, 2016).

Nuestra segunda apuesta toma en consideración que la inconstante constitución relacional que parece caracterizar a las entidades que participan de la vida social mapuche tiende, al incluir nuevas partes-relaciones sociomateriales, a una alteración difícilmente previsible que es, sin embargo, autodeterminada por su infraestructura. Esto nos lleva a proponer lejos de la posibilidad de desentrañar un marco general a partir del descubrimiento de una continuidad semiótica, donde el relacionamiento de todos los seres es conmensurable (Kohn, 2013) que el potencial ontológico de las entidades, actualizadas permanente y diferentemente por distintas relaciones sociomateriales, genera continuamente nuevos mundos de plano inconmensurables (Nadasdy, 2007; Povinelli, 1995, 2001). Desde ahí, nuestro artículo ofrece una reflexión cosmopolítica, en tanto demuestra, siguiendo el trabajo de Marisol de la Cadena (2010), distintas equívocas concepciones del mundo material y su agencia (Viveiros de Castro, 2004). En esta línea, pretendemos problematizar la posible comprensión de la interacción entre entidades previamente no relacionadas humanas y no humanas como un "evento", en el sentido que dan a este término Meinert y Kapferer (2015). Esto es, como un pivote que reafirma y realiza un potencial que se encuentra en la misma constitución de las entidades que entran en interacción. Luego, ofrecemos un análisis etnográfico sobre el papel que juega la autodeterminación ontológica de las infraestructuras en sus propias transformaciones². Esta idea evoca, al menos merográficamente (veáse Strathern, 1992), debates epistemológicos en teoría sistémica iniciados por el mismo Bateson, y desarroIlados más tarde, entre otros, por los biólogos chilenos Humberto Maturana y Francisco Varela a través del concepto de "determinación estructural". Este establece que todos los cambios de un sistema "están determinados por su estructura, cualquiera que ésta sea, y en los cuales estos cambios estructurales se dan como resultado de su propia dinámica o desencadenados por sus interacciones" (1984: 64, nuestro énfasis). En lo que sigue, no nos interesar imponer estas teorías y sus meta-lenguages a nuestros materiales etnográficos. Lo que más bien pretendemos es señalar que, a la luz de un análisis etnográfico del metabolismo infraestructural producido por un camino, tal idea de "determinación estructural" parece recobrar su fuerza conceptual más allá de los fundamentos biologicistas de la teoría sistémica, dado que los materiales de las infraestructuras, cualquiera que esta(s) sea(n), no son jamás unívocos ni definitivos. Así, nos interesa sugerir en este trabajo que cualquier indagación que intente explorar transformaciones infraestructurales, necesita soportarse en un análisis etnográfico que dé cuenta de las propiedades materiales específicas que constituyen la infraestructura, y de alguna y otra manera, la auto-determinan de maneras insospechadas.
2 Para una revisión analítica de los debates actuales sobre auto-determinación ontológica, véase Holbraad, Pedersen y Viveiros de Castro (2014). 


\section{LUGARES EN EL SUR DE CHILE}

Las experiencias etnográficas que dan origen a este trabajo tuvieron lugar en dos localidades indígenas mapuche y mapuche-pewenche de la Octava Región del Bío Bío, en el sur de Chile. Históricamente, el río Bío Bío ha jugado un rol preponderante en la relación entre la población mapuche y distintos extranjeros. En 1641, fue declarado como la frontera que separaba a los españoles de los mapuches, aunque funcionaba como tal desde al menos 1598, luego de la histórica derrota del ejército hispano en la batalla de Curalaba (Millalén, 2006). Con posterioridad a estos eventos, el Bío Bío permaneció como la frontera septentrional de los territorios mapuche por más de dos siglos, aunque permitiendo un constante relacionamiento e intercambio entre ambos lados de ella (Boccara, 2007). En lugar de impermeabilizar totalmente el contacto de las entidades que separaba, la frontera funcionaba como una delimitación sociomaterial porosa que permitía un contacto continuo entre los lados que distinguía (Bashkow, 2004). Este contacto se dinamizó e incrementó exponencialmente, de manera posterior, con la instauración del Estado Chileno (Bengoa, 2000). De esta forma, las relaciones entre poblaciones mapuche y extranjeras tienen larga data, gozando por mucho tiempo de una declarada y práctica horizontalidad a través de la "frontera" del Bío Bío (Foerster, 2004). Sin embargo, con la formación del Estado y la disolución formal de la frontera, aumentó abismalmente el flujo a través de ella, permitiendo la instalación chilena y la ocupación militar de los territorios mapuche desde la década de 1860. Como corolario de este proceso, el Estado chileno introdujo una política de radicación de las poblaciones indígenas, reconociendo la propiedad consuetudinaria de tan solo un $10 \%$ del territorio mapuche ancestral ${ }^{3}$. Esto provocó, posteriormente, una creciente escasez de tierras, que gatilló a su vez un extendido proceso de migración campo-ciudad durante todo el siglo xx, que algunos han descrito comparativamente como la "diáspora mapuche" (Ancán y Calfío, 1999). Gracias a esta diáspora, en la actualidad, la mayoría de la población mapuche habita en áreas urbanas de Chile. Por su parte, los mapuche que aún permanecen en los remanentes de sus territorios ancestrales han debido lidiar, entre otras cosas, con la expansión de la industria forestal incentivada por la dictadura militar que ocupa, en la actualidad, 2.201.581 HA que corresponderían al territorio ancestral mapuche (Aylwin, Yáñez y Sánchez, 2013) y con la expansión asistencial y subsidiaria desarrollada desde el retorno a la democracia chilena en 1990. Estos procesos, en su conjunto, han provocado la articulación de diversos movimientos mapuche de resistencia. Como respuesta a ellos, desde el año 2000, más de un centenar de mapuche han sido encarcelados por acciones relacionadas con reivindicaciones territoriales, entre los cuales una cincuentena han sido acusados y procesados bajo una ley

3510.386 HA de un total aproximado de al menos 5.000.000 HA (Conzález, 1986). 
antiterrorista heredada de la ya referida dictadura (Correa y Mella, 2010; Bonelli y Vicherat Mattar, en prensa).

En las localidades donde trabajamos la comunidad de Pitril, en la cordillera andina de Alto Bío Bío, y el valle de Elicura, cerca de la costa pacífica en la provincia de Arauco también se manifiesta el contacto que hemos descrito, aunque con algunos matices. En la primera, la interacción entre mapuche-pewenche $y$ chilenos ha existido durante todo el siglo xx y parte del XIX, sin embargo generalmente de forma esporádica y fragmentaria, dada la situación relativamente aislada que presenta este lugar enclavado en la Cordillera de los Andes, donde hasta hace unos 30 años no existía camino alguno que permitiese transitar con facilidad entre el valle del Queuko donde se ubica Pitril y diversas localidades chilenas más urbanizadas ubicadas hacia el poniente. De modo diferente, el valle de Elicura ha sido una zona de contacto entre mapuche y no-mapuche desde inicios de la conquista, ubicándose en una posición estratégica entre la zona de Arauco y Purén-Lumaco, dos nodos neurálgicos durante este proceso. Con el paso de los años, y con mayor intensidad luego de la independencia de Chile, Elicura continuó siendo un lugar en cuyas cercanías transitaban personas de diversa proveniencias, incluyendo importantes números de colonos alemanes y chilenos ${ }^{4}$

A pesar de esta aparente diferencia en la intensidad y extensión del contacto, estos elementos, tanto en Pitril como en Elicura, parecen no ser realmente relevantes en la reflexión que la gente hace sobre la alteración que han sufrido sus vidas, sus relaciones y sus mundos. Aun cuando esta alteración pueda relacionarse con la subordinación, con la violencia estructural y con el colonialismo, contrario a lo que podría esperarse, estas variables no son relevadas como las causas centrales de aquellos cambios y, aunque son consideradas, usualmente se encuentran subyugadas a un suceso infraestructural específico. Como veremos, la transformación tendría que ver, simple y llanamente, con la construcción o mejoramiento de un camino. Considerando esto, el ejercicio que nos hemos propuesto experimentar en este artículo es el de considerar al camino como un enigma a ser descifrado etnográficamente: solo sabremos lo que es un camino si exploramos lo que un camino hace y sus capacidades (véase Deleuze y Guattari, 1987).

Antes de comenzar esta exploración, vale una importante aclaración. Tradicionalmente, en la vida mapuche rural, los caminos rupü en chedungun han gozado de un importante nivel de atención, siendo un elemento recurrente en historias, proverbios y otros géneros narrativos. Un ejemplo de esto son los relatos sobre la vinculación transcordillerana (Fernández, 1999), el papel que se adscribe al camino como un potencial visualizador del destino personal (Course, 2014), y especialmente la manera en que muchas narrativas mapuche están aso-
4 Estos matices con respecto al contacto evidencian una diferencia, por ejemplo, en la realidad lingüística de ambos sectores. Así, mientras en Pitril hay una importante concentración de hablantes bilingües en castellano y chedungun (en todo Alto Bío Bío, en general, habría un 90,7\% de población bilingüe), en Elicura, el porcentaje de población bilingüe parece ser mucho menor, rondando en torno a un 40\% (Gündermann et al, 2008; Teillier, 2013). 
ciadas tanto a viajes, que implican transitar o hacer caminos (González Gálvez, 2016), como a relevar los caminos como lugares donde se producen encuentros (Koessler-Ilg, 2007). Estos caminos, no obstante, parecen ser de un tipo diferente a los caminos construidos por el Estado chileno, aquellos que provocarían la alteración infraestructural de los mundos vividos mapuche. Para comprender esta diferencia, es necesario trazar una distinción entre los nuevos caminos chilenos, y los antiguos caminos mapuche. Estos últimos, en la actualidad, son referidos simplemente como "huellas". Así, como su mismo nombre lo indica, estos parecen ser concebidos como los remanentes de tránsitos previamente emprendidos, que pueden ser seguidos o no en la persecución de una relación. En otras palabras, las "huellas" son los vestigios de relaciones previamente establecidas, cuya creación se debió justamente a la deliberada acción de querer establecerlas. De modo similar a como señala Allerton (2013), entre los manggarai de Indonesia, el establecimiento de relaciones crea senderos que se inscriben en el paisaje y que son el remanente de una conexión real; si dicha conexión no es actualizada de manera constante, ellos desaparecen. Además, son libres, en tanto su construcción personal puede o no estar influenciada por el trazo de huellas anteriores, siendo siempre posible la creación de un sendero completamente nuevo. De modo diferente, los caminos nuevos, aquellos impuestos desde el exterior, tienen la pretensión de facilitar el establecimiento de relaciones, uniformando y facilitando el tránsito para la consecución de ello. Estos caminos están hechos para permanecer y normar los movimientos, haciendo inviable la emergencia de construcciones personales de "huellas" alternativas. Finalmente, y quizás de modo más importante, estos caminos, a diferencia de las "huellas", permiten el tránsito permanente y continuado de "cosas ajenas", como veremos a continuación.

\section{EL CAMINO Y LAS COSAS AJENAS}

Hoy en día, las distintas comunidades del valle del Queuko (Pitril, Cauñicu, Malla Malla, Trapa Trapa, Butalelbun) se encuentran conectadas por un camino rural (Figura 1), construido en la década de 1980. Este camino es muy importante para los habitantes de este valle, no solo porque permitió a muchas personas tener un

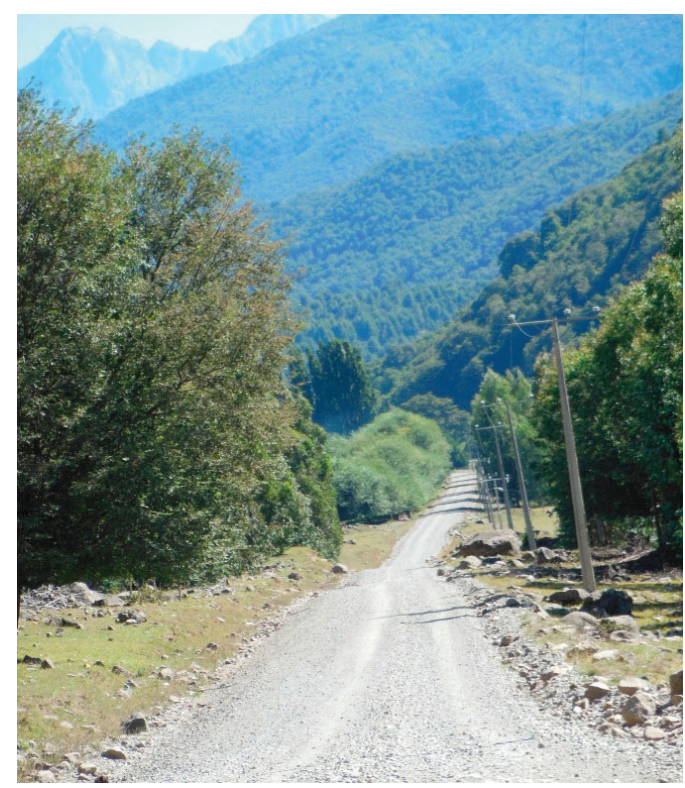


trabajo durante los varios años que duró su construcción, sino también porque fue a través de él que empezaron a llegar a las comunidades una importante cantidad de objetos que antes no existían. En efecto, el camino ha representado para muchos la posibilidad de acceder a los beneficios de la vida chilena, a la "comodidad" del trabajo asalariado, a las comidas de supermercado, al agua caliente, etc. Sin embargo, también ha representado, como señalaba un anciano de Pitril, el inicio de un gran desorden: "El camino trajo un gran trajino, permitió la llegada de un sinfín de 'cosas ajenas' (ka yewum)".

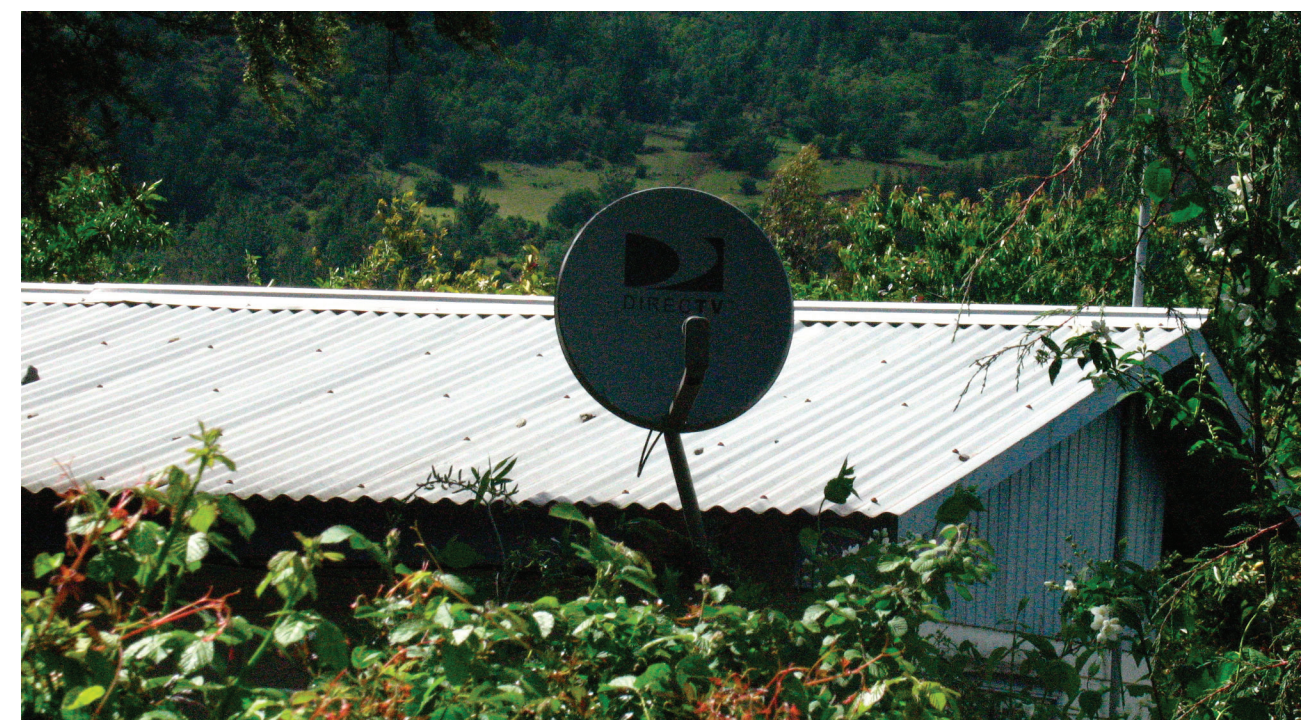

Mucha gente en el valle del Queuko habla del camino como la entidad que gatilló el cambio de "mentalidad" en las nuevas generaciones, a través de la incorporación de cuestiones exóticas, tales como materiales de construcción para nuevas casas, escuelas públicas, postas de salud, comerciantes, ropa, comida chilena, dinero, teléfonos celulares, televisores y, más recientemente, internet y televisión satelital. Este abanico de "cosas ajenas", además, tuvo un impacto en los habitantes no humanos del valle. En palabras de otro de los habitantes de Pitril,

Todo ese trajino llevó a que hoy en día se vean mucho menos apariencias andando por aquí... Muchas apariencias decidieron irse a otro lugar debido a este trajino... Por ejemplo la wacako [vaca de agua] no se ve más, tampoco el culebrón se ve más, ni ese pájaro depredador llamado piuchen... Todos esos seres que veíamos en el pasado se han ido yendo... De hecho, el mismo ser este que me viene a visitar en las noches y me chupa la sangre, ya no visita a la gente más nueva... Ese, el witranalwe, quizás por todas esas inyecciones que le ponen a la gente nueva, la sangre de los jóvenes no le gusta más, no le gusta la sangre mezclada con inyecciones... 
De manera importante, la llegada del camino implica, en la práctica, el desuso de las tradicionales "huellas", donde usualmente ocurrían los encuentros con las apariencias; es más, la llegada del camino implicó muchas veces la desaparición tanto de las "huellas" como de las apariencias. Aí, la retirada de las apariencias puede ser vista como una respuesta a la llegada del camino y su trajino, evento en el que la infraestructura vial altera, insospechadamente, la distribución del mundo sensual indígena. En este sentido, y haciendo eco de algunas reflexiones de Jacques Rancière, se podría decir que el camino ha tenido un efecto "político" en el mundo mapuche-pewenche, en tanto ha producido una nueva "distribución de lo sensible", de lo visible, de lo hablable y de lo decible (2006: 121) ${ }^{5}$. Lo que parece estar en juego, aquí, es una redistribución de lo sensible en la que el camino no solo se presenta como una tecnología de la conexión, sino que simultáneamente opera como una tecnología de la distanciación (Pedersen y Bunkeborg, 2012). Esta distanciación se realiza, sin embargo, a partir de la comprensión de los materiales sensibles preexistentes al camino en el valle, en donde las apariencias deciden, autónomamente, tomar distancia respecto de aquella otra materialidad soportada y transportada por el camino. En cierto sentido, el camino es capaz de alterar la frontera virtual que existía entre los variados seres que habitaban el valle, entre apariencias y humanos. Como tecnología de la distanciación, el camino posibilita y gatilla un arranque en partida doble: los más jóvenes deciden emigrar hacia los sectores urbanos de Chile, mientras que las apariencias deciden partir hacia lugares inciertos para los propios habitantes del valle, produciendo así una extensión del mundo virtual que las acoge en exilio voluntario. Para decirlo con un lenguaje Batesoniano, lo que el camino altera es la cadena de diferencias propias de la mente inmanente: aquello que generaba unidades de información en el mundo del valle antes del camino.
5 Para aproximaciones similares, véase Bennett (2010) y De la Cadena (2010) forman parte de la continuidad del newen. Importantes ejemplos de estas son las "piedras machi" de Alto Bio Bio, y los likan de Elicura, piedras animadas vinculadas a los volcanes. Una famosa piedra, que manifiesta de manera especial el newen, es explorada por Schindler y Schindler-Yañez (2006).

Figura 3: Piedra de Pitril

LO QUE EL CAMINO LE

\section{HACE A UNA PIEDRA}

La piedra que aparece en la fotografía se encuentra situada al borde del camino recién descrito, que conecta el valle del Queuko con el pueblo chileno más cercano, Ralco. Entre los habitantes del valle, esta piedra es conocida por estar dotada de mucha fuerza, o newen ${ }^{6}$. En la cosmológica mapuche, newen es la fuerza inmanente, continua pero

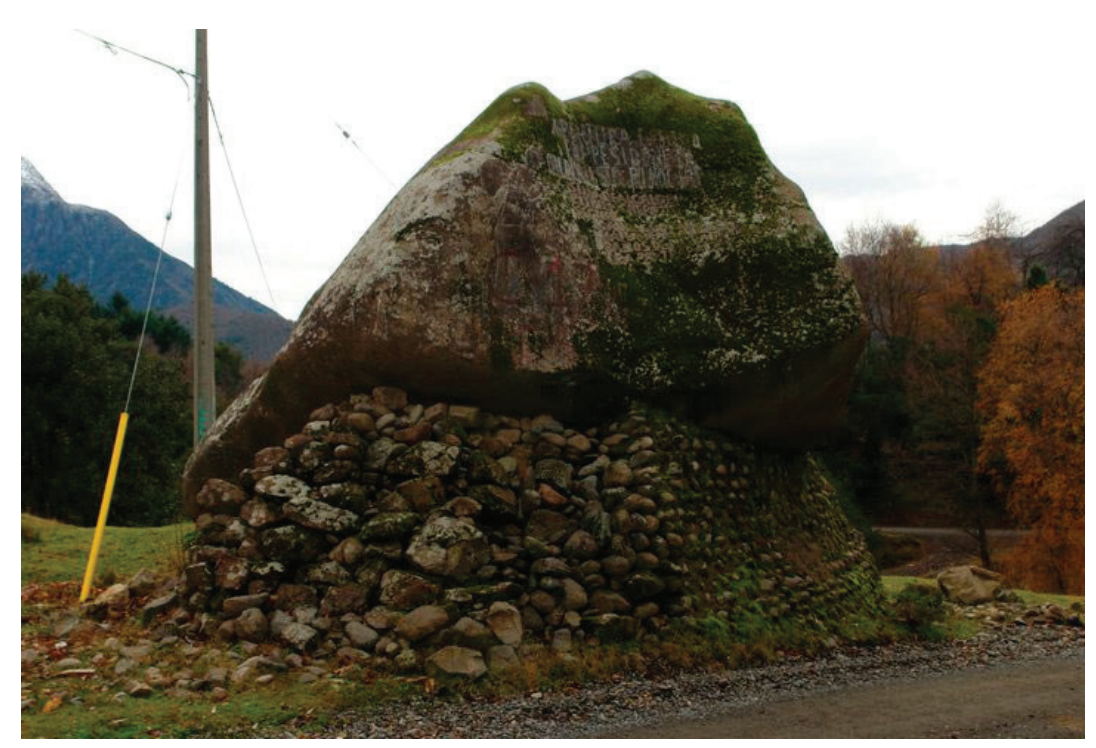


fluctuante (Course, 2012), que se manifiesta en, y es común a, todos los entes que habitan el mundo indígena. Diferentes entidades pueden manifestar esta fuerza intrínseca de la tierra: desde un lugar a una persona, desde un árbol y un río, hasta ciertamente una piedra. Esta fuerza expresa, además, capacidades particulares inmanentes que varían de entidad a entidad, y cada ente manifiesta este newen en intensidad diferente. Hay entidades cuya fuerza es prácticamente imperceptible para los otros, teniendo poca posibilidad de interactuar con ellos. Otras, de las cuales la piedra ilustrada en la fotografía es un ejemplo, están dotadas de tanta fuerza que su presencia no pasa jamás desapercibida.

En efecto, esta piedra, así como todo lo que la circunda, son recordados vívidamente por los habitantes del valle como un lugar muy importante dentro de la historia de Pitril. Esto, porque el newen de la piedra permitía a los antiguos probablemente, a aquellos que poseían ciertas cualidades chamánicas "ver el futuro", obtener visiones sobre el porvenir de las comunidades del valle. Esta caracterización probablemente le resulte extraña al lector que se identifique con el "hombre occidental promedio" mencionado por Bateson en el epígrafe. Después de todo, desde este "hombre occidental promedio", las piedras son objetos inertes: no tienen fuerza, no pueden otorgar ninguna capacidad en relación con ningún otro, y por supuesto, están absolutamente separadas de la capacidad humana de percibir el mundo7. Como sea, durante las últimas décadas, la fuerza o newen de esta piedra se ha visto alterada. De hecho, en la actualidad, ella ya no es conocida solamente como ese lugar con newen donde aquellos con dotes chamánicos podían acceder a otras dimensiones y "visualizar" el porvenir. Hoy en día, ella no es un renü como se solía llamar a esos lugares poderosos de encuentro chamánico, sino que es conocida como "la piedra de Pinochet", y en ella se puede ver-leer lo siguiente:

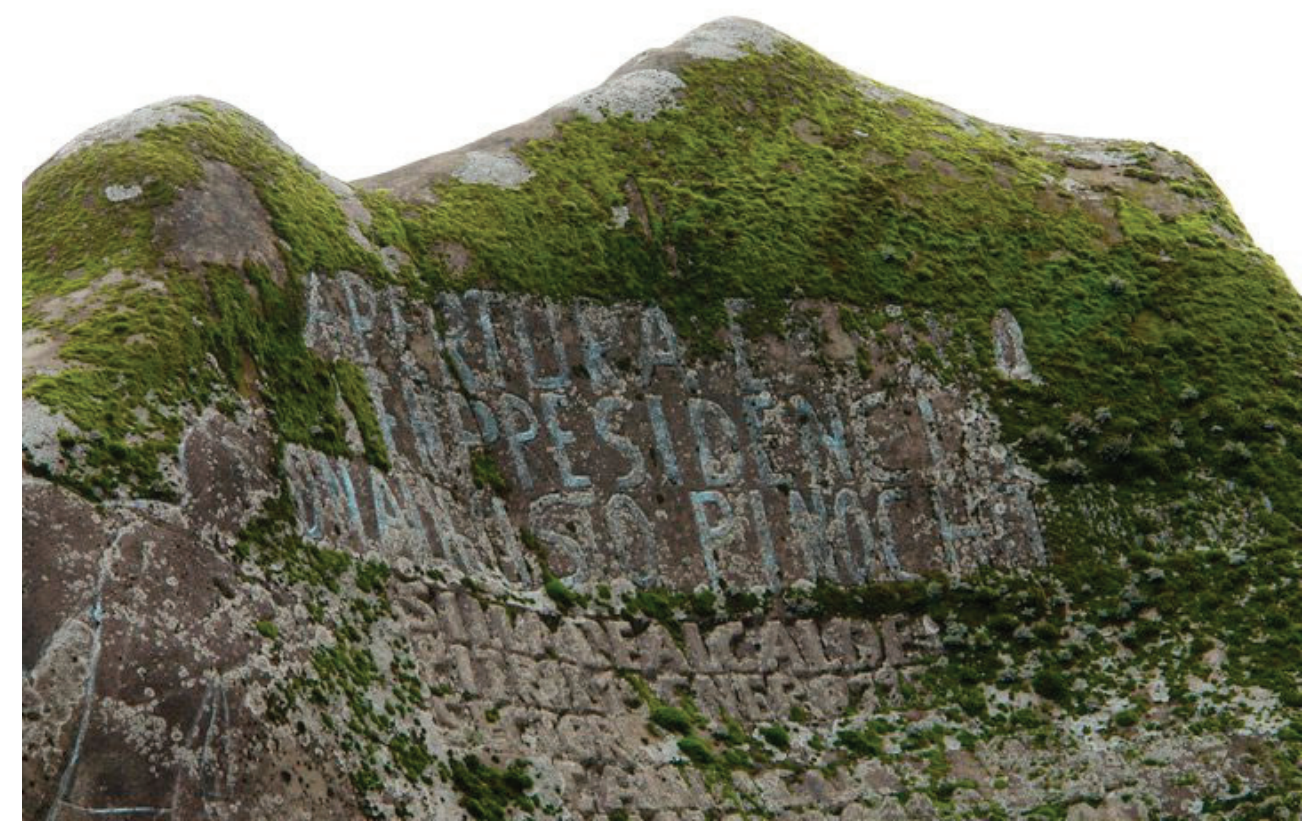

7 Como discute Povinelli (1995) para un caso similar, la descripción mapuche-pewenche es, en este sentido de plano, convertida en creencia y, así, subordinada a discursos que podrían estimarla solo en la expresión de valor patrimonial, nunca como una descripción ajustada a la "realidad" (Bonelli, 2012; Di Giminiani, 2013; Conzález Cálvez, 2015).

\section{Figura 4:}

Inscripción en la piedra "Apertura del camino Presidente Augusto Pinochet" 
En la vida cotidiana, ella sirve como punto de referencia para ubicar a los habitantes de Pitril, y separa lo que hoy se conoce como Pitril bajo y Pitril alto. Pero también es un elemento que expresa la historia del valle y sus drásticas alteraciones sociomateriales. La piedra rememora la historia de los últimas décadas del lugar, y nos obliga a imaginar y recordar a uno de los dictadores más crueles de la historia latinoamericana. Este personaje, sin embargo, es en Pitril recordado como el "primer presidente de Chile" que hizo algo por las comunidades, abriendo un camino y dando empleo a los habitantes del valle, que fueron contratados para la faena ${ }^{8}$. En palabras de Renato, uno de los habitantes de Pitril:

Esa piedra tiene una historia, no es una piedra así nomás. Es una piedra santa donde había newen... Esa piedra es muy grande, dos máquinas no pudieron sacarla... Quedó al lado del camino nomás, no pudieron moverla, porque esa piedra era un renü donde había mucho newen, donde la gente que tenía mucho conocimiento de espiritualidad, iba a esa piedra para saber cómo íbamos a estar en 50 años más, en 60 años, en la actualidad de hoy... Cuando pasó el camino por ahí, las máquinas empezaron a romper, romper, romper, y se dieron vuelta camiones, murió gente, y no la pudieron sacar, y como quedó tan linda, y quedo ahí... Y hicieron la cuestión [la inscripción] de Pinochet, es como un monumento que le hicieron a Pinochet por todo lo que había hecho, por el camino, por el sueldo mínimo que le pagaba a la gente para construir el camino...

Las referencias a Pinochet, al camino y a la piedra podrían ser consideradas como evidencia de que las infraestructuras expresan proyectos políticos más amplios (Larkin, 2013). Sin embargo, nos parece que la administración Pinochetista, de la cual se habla en la inscripción sobre la piedra y en las palabras de Renato, persiste no por la fuerza que tiene el Estado para expresarse infraestructuralmente, sino, más bien, por una especie de determinación infraestructural de la fuerza material del mundo mapuche, a saber, su newen. En este sentido, este escenario evoca la descripción que Marisol de la Cadena hace de una protesta indígena en Perú en contra de proyectos mineros en la montaña Ausangate, que para los indígenas constituía una entidad no humana un ser de la tierra conocido como tirakuna con la capacidad de "enloquecer, e incluso matar a gente" (2010: 339). Tanto en el caso de Pitril como en el de Perú, estamos en presencia de entidades que están lejos de ser "naturalezas" sin fuerza ni agencia. De hecho, mientras Ausangate tiene la agencia y fuerza de cualquier persona humana, el renü aparece como un potenciador de la agencia visiva más allá de lo humano. No obstante, el punto que quisiéramos resaltar acá es que la materialidad de la piedra indica un evento etnográfico distinto, ya que nos muestra al go sobre la transformación inmanente de la materialidad de las cosas sin invocar necesariamente mo-
8 Una exploración general sobre el lugar de la figura de Pinochet (y de los principales líderes políticos winka) en la vida mapuche puede observarse en Foerster y Menard (2009). 
vilizaciones indígenas que cuestionen la univocidad y objetividad de la política moderna para la cual las piedras son piedras inertes y las montañas, montañas inertes. El caso de la piedra de Pitril no implica, en principio, una oposición entre mundos, sino simplemente testimonia la transformación de un mundo material afectado por fuerzas y materialidades heterogéneas. En este sentido, consideramos preciso trazar una conexión con el reciente trabajo de Jensen (2016) sobre la necesidad de desarrollar una "antropología de infraestructuras descentrada", es decir, una antropología que no imponga a priori el límite donde los materiales terminan y los imaginarios comienzan ni que se base en distinciones predeterminadas sobre la separación sujeto-objeto, sino más bien que considere las formaciones sujeto-objeto como resultados emergentes de procesos relacionales y materiales (Jensen, 2016). Dicho de otro modo, las relaciones interculturales gatilladas por el camino debieran ser consideradas como relaciones intersociomateriales que alteran, en modos contingentes e insospechados, distintas versiones de fuerzas sensibles autodeterminadas. Estas relaciones transforman el valle, $y$ un ejemplo de estas transformaciones se encuentra justamente en la piedra y en el debilitamiento del newen que esta solía tener. Hoy en día, la capacidad visiva y la fuerza de la piedra parecen estar paralizadas en el tiempo, y a parecen como índices de un pasado que existió "antes del camino". Pero ese pasado late aún vivo, inmanente en la presencia de la piedra que persevera en su estar allí.

\section{LO QUE EL CAMINO LE HACE A LOS CERROS}

Paralelamente, a un par de cientos de км al Suroeste del valle del Queuko, у a unos $20 \mathrm{KM}$ del mar, el valle de Elicura mostraba, en 2010, una cara completamente diferente a la que presentaba tan solo algunos años antes. Ubicado a un costado del camino que une los pueblos de Cañete y Contulmo, el valle no era ajeno al menos tangencialmente a un profuso contacto con el exteriory sus cosas ajenas. Sin embargo, por tangencial que fuese, esta vinculación hacía patente que el lugar carecía de elementos que eran considerados, en ambos pueblos y desde una lógica chilena, esenciales para la vida. Primero electricidad, alumbrado público, alcantarillado, agua potable. Luego, señal de teléfono celular, de Internet y de televisión. No obstante, en una década, todo cambió de súbito. Quizás, demasiado rápidamente.

La gente consistentemente explicaba este cambio a través de un evento que no dejaba de ser sorprendente: todo se había desencadenado a partir del mejoramiento del camino interior del valle. Años atrás, las distintas localidades del valle de Elicura estaban conectadas por un camino de tierra, pobremente enripiado, que se transformaba en un barrial al cabo de unas cuantas horas de lluvia y que se convertía en un brazo del río Elicura cuando las Iluvias se extendían por 
un par de días. A comienzos de la década del 2000, se construyó un dique para contener las crecidas de río y se asfaltó el camino. A través de él, durante los 10 años siguientes, Ilegaron y se asentaron la electricidad y el Internet, los celulares y el agua potable. No solo por esto había sido importante el camino, por permitir la entrada de aquello que mejoraba la "calidad de vida", sino también porque proveía los medios de acceso a esta mejora. Como en el Queuko, las obras relacionadas con él generaron numerosas posiciones de trabajo para la gente del valle, y las sigue generando, en la actualidad, a través de programas de mantenimiento de la infraestructura vial y de un plan de trabajos de emergencia (que es más bien permanente), gracias al cual muchas personas pasan el año completo limpiando de malezas la berma del camino, sin un fin práctico demasiado evidente.

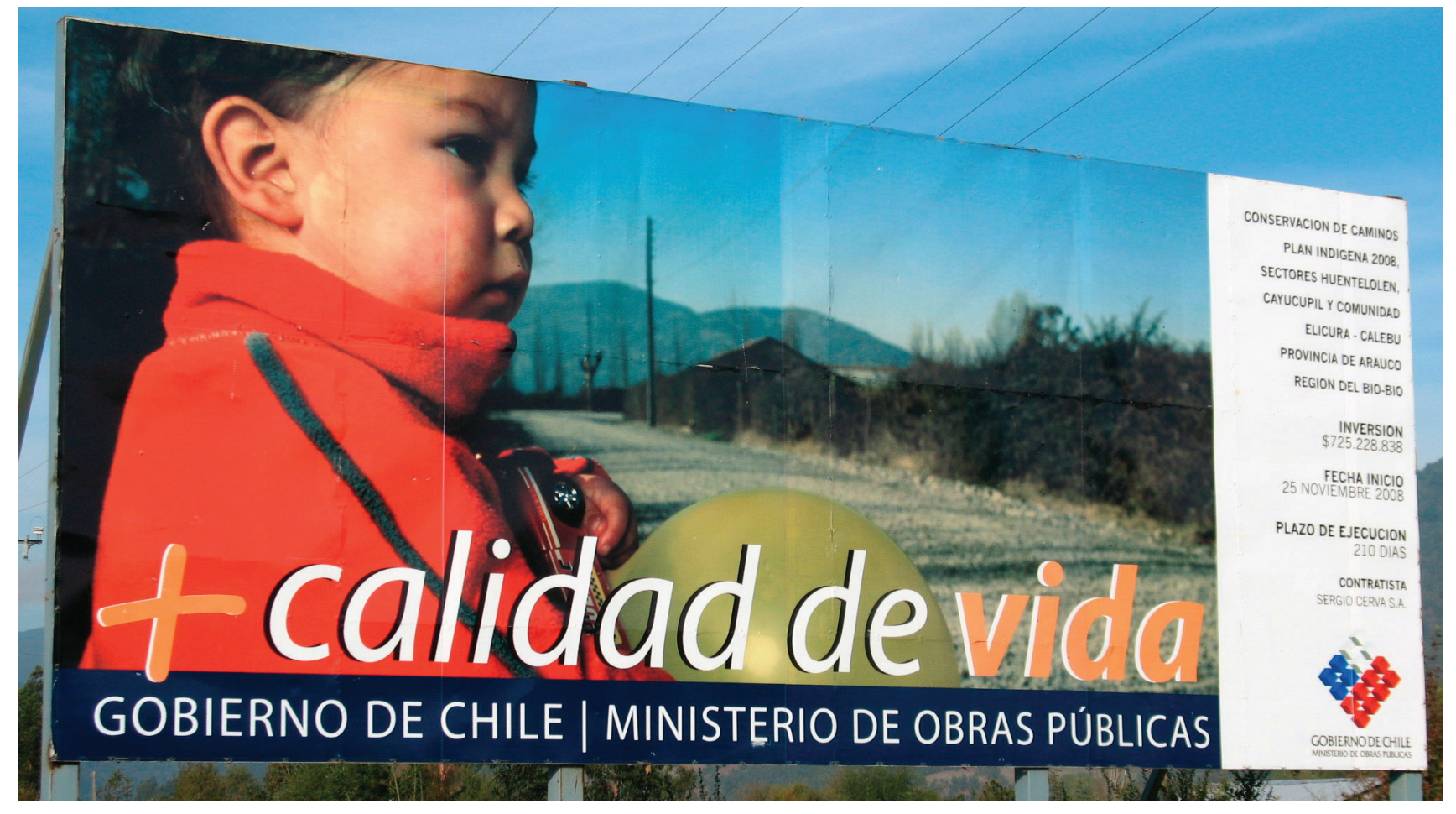

Más allá de esto, esta modificación sociomaterial, que permitía un mayor, más expedito y más ordenado tránsito entre el valle y el exterior, tuvo un impacto en ción caminera la constitución precaminera del lugar. En el sentido de Jensen (2015), el camino se hizo parte de la "infraestructura ambiental", siempre relacional y contingente, reconfigurándola a partir de su propia reconfiguración, de su asfaltado y mantenimiento. Dicha reconfiguración se manifestó, por ejemplo, en la desaparición o invisibilización de entidades que, en un momento anterior, formaban parte importante de la vida cotidiana y que poblaban abundantemente los cerros que encajonan al río Elicura. Un ejemplo de esta invisibilización, como sucedía en 
Pitril, se encuentra en la migración de apariencias y otros seres virtuales que habitaban los cerros antes del mejoramiento caminero. Como contaba un antiguo habitante de Elicura:

Cuando éramos niños se veían muchos anchimalenes ${ }^{9}$, casi siempre en el cerro... En ese tiempo mi papá tenía un terreno en el bajo, y todos los años plantaba papas. Entonces, cuando había que cosecharlas, nos íbamos con mis hermanos a dormir allá varios días. Armábamos una rancha y nos quedábamos de noche cuidando lo que habíamos sacado. Después, en la noche, empezaban a aparecer los anchimalenes... Siempre de noche... Se veían a unos doscientos, doscientos cincuenta metros, como flotando en el cerro... A nosotros nos daba mucho miedo, y nos tapábamos juntos para no ver que estaban allá a lo lejos... Esas eran las cosas que pasaban antes, pero a hora ya casi no se ven...

Estas entidades no son las únicas que "casi no se ven" desde que ocurre la reconfiguración, sino también desaparecen otras que formaban parte fundamental, y literal, de los procesos metabólicos que tenían lugar en el valle. Esto se asocia directamente a una alteración más radical en la salud de la gente, que contrasta con una etapa anterior donde esta solo podía ser trastocada por la intencionalidad subjetiva directa de un tercero, humano o no humano. Hoy, al contrario, los cuerpos-alterados mostrarían una situación diferente, donde la enfermedad es consubstancial al cuerpo y no hay necesidad de ninguna agencia exterior para provocar la muerte. Como nos explicaba una anciana del lugar:

Ya no es como antes, que la gente no se enfermaba... Lo que pasa es que todo ha cambiado... Antiguamente las comidas eran más naturales... Hoy en día no... Hoy, uno va al pueblo y se compra unos fideos, unos paquetes de arroz, unas bebidas, iy eso come!... ¡Antes no poh! Antes se comía trigo partido, catutos, milcao, harina tostada... Del río se sacaba un camarón chiquito asíy dellom, una macha chica... Del cerro sacábamos changle, dihueñes y murtilla... ¡Pura comida natural!, jsin ningún químico!... Pero a hora ya casi no queda nada de eso... Se acabó todo...

Como el hermano de Francisco, que es transformado por la alteridad material, el valle de Elicura o, más precisamente, sus cerros, antiguo hábitat de anchimalenes y comidas naturales son alterados sociomaterialmente a partir del mejoramiento del camino, lo que permite distinguir dos momentos temporales abiertamente distintos del valle y de los cerros. Como decía un anciano, que "este mapu (tierra) ya no es el mismo que el mapu antiguo, porque hace cuarenta años por ejemplo no estaban las montañas que están aquí ahora. Antes habían otras
9 Anchimalenes son entidades descritas "como luces", "como bolas de fuego", o "como luciérnagas grandes", usualmente perceptibles desde una gran distancia. En el pasado, habrían estado asociados a los "brujos" (Montecino, 2003). Dicha conexión aparece, sin embargo, como inexistente en Elicura, donde los anchimalenes eran/son comúnmente concebidos como entidades autónomas. 
montañas, otras donde había mucho mognen (vida), mucha vida había ahí... Otro vill mognen" (aprox. "todo lo vivo").

En Elicura, esta alteración caminera presenta una dimensión adicional que ha incidido fuertemente en la redistribución de lo sensible, radicalizando la invisibilización de anchimalenes, alimentos naturales y "árboles nativos", y haciendo aparecer nuevos habitantes, entre los que destacan los pinos radiata y eucaliptos (Figura 6). Esta dimensión se relaciona con la introducción de prácticas, objetos y tecnologías asociadas a la industria forestal.

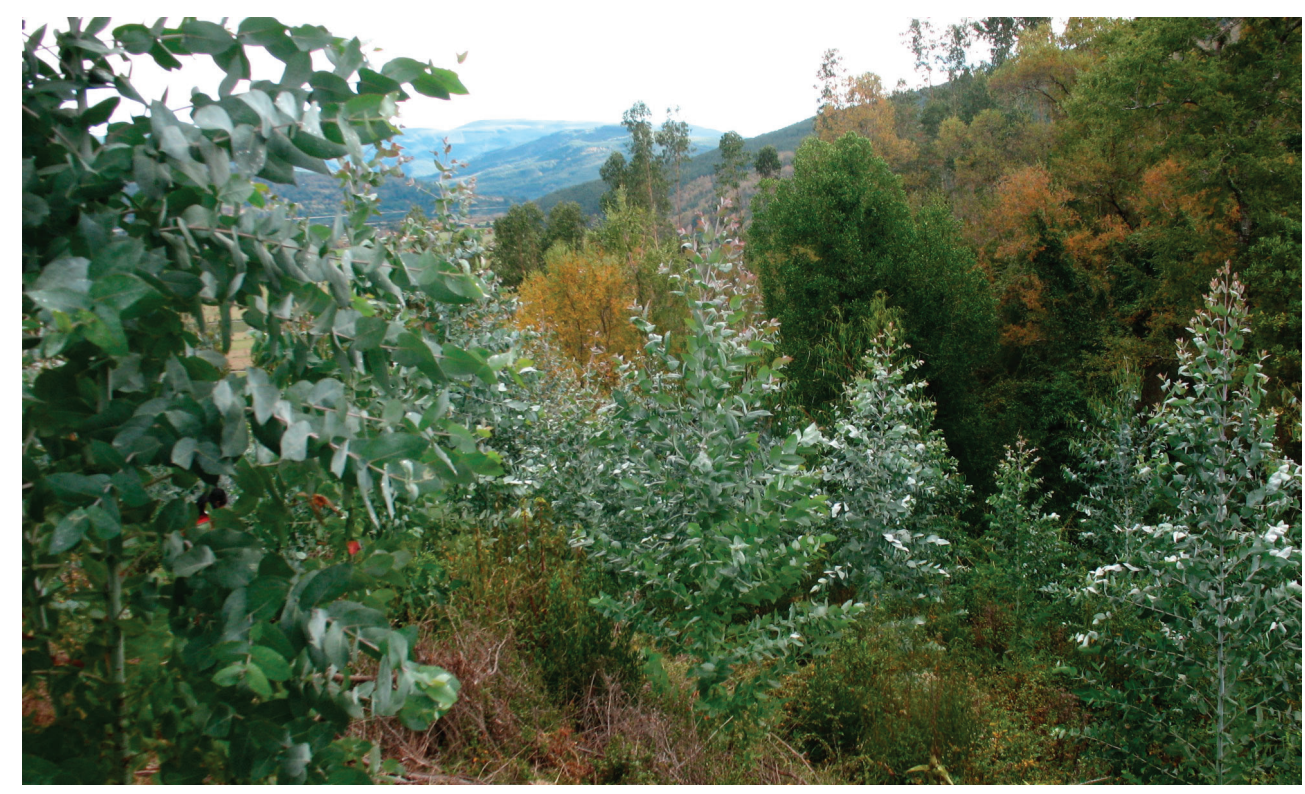

Este conjunto de prácticas-objetos signados con la etiqueta "las forestales" es un ejemplo particular de la materialidad que ha alterado los mundos indígenas, en tanto manifiesta patentemente la tensión de la alteración que se produce a partir de la interacción de estas "cosas ajenas" con las cosas que estaban en el lugar antes del camino. Esta tensión aparece a partir de que ambas agencias ajena e indígena presentan lógicas mutuamente repelentes, puesto que la constitución relacional del lugar observa un complejo equilibrio de autonomía y respeto entre sus partes constituyentes (Course, 2011), mientras que lo ajeno pasa por alto y transgrede ese equilibrio. Evocando la imagen de la frontera, la primera agencia tendería a mantenerla y defenderla, mientras que la segunda a deshacerla. Si las relaciones precamineras parece caracterizarse por la observación de una lógica de las "buenas distancias" (Foerster, 2004) donde cada entidad intenta no interponerse en la intencionalidad subjetiva de los otros, al tiempo que espera que los otros no se interpongan con su propia intencionalidad subjetiva, las prácticas y materialidades ajenas entre las cuales las forestales son de las más importantes intentan, en su máxima expresión, la apropiación 
del otro humano o no humano y/o su objetivación y desagenciamiento. Este tipo de prácticas, sobre todo cuando son ejecutadas por personas humanas, son usualmente clasificadas bajo la etiqueta winka (no mapuche) y explicadas a través de un afán maximizador que, no en vano, la gente describía como un actuar "materialista". Como sintetizaba un antiguo dirigente del valle: "estos huevones [de las forestales] se creen dueños de todo... Arrasan con todo con tal de ganar unos pocos pesos... Total, si dejan la cagá y destruyen todo, se van a otro lado a seguir ganando plata... No tienen raíces". Considerando esto, la oposición se acentúa. Las prácticas y agencias ya no solo difieren moralmente, sino en su capacidad de movimiento. Mientras unas se encuentran enraizadas a los lugares y se configuran en la articulación ecológica de newen de entidades que habitan en ellos (Bonelli, 2015; Course, 2013; Di Giminiani, 2015), otras "no tienen raíces" y pueden movilizarse socioespacialmente sin impedimentos, lo que por cierto puede facilitarse y potenciarse con los caminos.

\section{MENTALIDAD ALTERADA}

Mientras nos contaba la historia de cómo se había convertido en ministro Pentecostal, un reconocido pastor mapuche de Elicura detuvo su relato y enfáticamente afirmó: "Finalmente tuve un pewma [aprox. sueño] que se me repitió varias veces... En ese pewma yo tenía que construir un camino... Siempre un camino... Mi señora me ayudaba, porque era muy difícil... Así fue que me llegó la confirmación, así fue que supe finalmente que Dios quería que fuera su pastor". Paralelamente, existe en Elicura un relato muy difundido que cuenta como perdieron los mapuche la mayor parte de su territorio ancestral. Esta historia, no por casualidad, comienza con un viaje que las personas del valle realizaron al norteño pueblo de Lebu. La peculiaridad de este viaje es que, según la gente, cuando se realizó, hace más de 100 años, no existía ningún camino para llegar a aquel lugar, por lo que la gente tenía que irlo construyendo a medida que iba avanzando.

¿Qué es lo que tiene el camino para ser empleado en estos y otros relatos, gatillando alteraciones? En nuestra impresión, nos parece que la respuesta a este interrogante se encuentra en la posibilidad de pensar productivamente los caminos como o en conexión con una infraestructura ambiental, en el sentido de Jensen (2015). Es decir, los caminos son en sí mismos además de ser parte de un sistema relacional-material, cuya perseverante modificación relacional permite la latencia/actualización de una multiplicidad ontológica. Asimismo, posibilitan la fricción entre distintas materialidades, permitiendo el relacionamiento de entidades que antes se encontraban aparte, separadas.

Alineado a esto, si consideramos todas las alteraciones descritas, en su 
conjunto, ellas evocan la mente inmanente imaginada por Bateson. Durante las últimas décadas, la "mentalidad" en ambos valles ha cambiado. Este es un hecho afirmado una y otra vez por nuestros interactuantes. Pero, característicamente, esta "mentalidad" asume una continuidad inmanente entre las cosas y los modos de pensar, entre la materialidad de las cosas y materialidad de la imaginación. Curiosa y coincidentemente, el cambio de "mentalidad", en ambos casos etnográficos, nos fue descrito como la progresiva aparición del "materialismo", actitud que habría surgido en las comunidades a través de la incorporación de nuevos "materiales" de construcción de casas. O sea, la gente se puso "materialista" debido a los "materiales de construcción":

Con el camino empezó el materialismo, se hacía adicta la gente, porque le entregaban aceite, grasa, pescado, una serie de cosas, una caja le entregaban a la gente, de alimentación... Y ahí donde se fue perdiendo lo nuestro, los valores, la unión... Antes se ayudaba la gente, si alguien estaba mal todo el mundo iba a ayudarlo, y después se le entregaron material de vivienda, entonces de ahí parte el concepto de materialista, el concepto para los más jóvenes es lo material, se deja de un lado a los ancianos...

Es evidente que este "materialismo" emergente refiere a una serie de conexiones materiales radicalmente distintas a las conexiones también materiales, pero en sus propios términos que posibilitaban las visiones chamánicas en torno a la piedra de Pitril, así como la existencia de apariencias y otros seres virtuales (o actuales) del mundo mapuche. Nos atrevemos a decir que este "materialismo" emergente, posibilitado por el camino, gatilló una transformación infraestructural que es determinada, valga la redundancia, por su propia infraestructura. El camino, de hecho, gatilla el retiro de las apariencias y otros seres de ambos valles, además del desgaste, al menos parcial, y en ningún caso definitivo, del newen de la piedra ${ }^{10}$.

\section{VISIONES VIRTUALES}

La alteración de la mentalidad y el rol que el camino ha ocupado como elemento alterador del valle no sorprendieron a muchos de los habitantes de Elicura y el Queuko. La misma mente inmanente que existía antes del camino ya había previsto, quizás como expresión de su infrareflexibilidad mítica, su propio devenir. De hecho, por ejemplo, en la comunidad de Cauñikú, colindante con Pitril, un grupo de personas pewenche se reunió hace algunos años alrededor de una preocupación común respecto a cómo las generaciones de "gente nueva" estaban cambiando de "mentalidad", olvidando su origen, sus antepasados, "materialismo" propio de los "materiales de construcción" evoca el trabajo etnográfico sobre infraestructuras habitacionales en territorios indígenas Australianos (Lea y Pholeros, 2010), que ha conceptualizado como "materialismo sucio" la relevancia práctica de las conexiones materiales particulares que permiten, o no, el funcionamiento adecuado de ciertas tecnologías. Sin embargo, la idea de "materialismo" expresada por nuestro interactuante deja en evidencia que el "materialismo sucio" de los materiales de construcción nada tiene que ver con los materiales imbuidos de newen del mundo mapuche, ni con la virtualidad material de las "apariencias" en retiro, ni con la materialidad y la fuerza que permitía el desarrollo de visiones chamánicas sobre el futuro. 
sus costumbres, su lengua, su comida, sus rituales y su sabiduría. Por ello, este grupo de hombres y mujeres adultos decidió realizar una grabación audiovisual para entregar un mensaje a los más jóvenes, para compartir con ellos algunas "visiones" que los más antiguos habían tenido sobre el futuro. Dado que los más jóvenes no querían escuchar el mensaje de los más antiguos, el uso de la televisión y de la tecnología digital sería un buen canal para llegar a ellos, pensaron los más viejos. De alguna manera, se podría decir, las visiones ancestrales que llegaban del remoto pasado sobre el futuro porvenir (las que llamaremos "tele-visiones chamánicas"), podrían ser expresadas a través de tecnologías tele-visivas, transportadas a través de imágenes en la pantalla (de la tele-visión mediática). La "distancia” implicada en la tele-visión chamánica y la tele-visión mediática difieren: mientras la primera es una distancia mítica, para la cual el futuro puede ser visto, previsto y actualizado, la segunda indica una distancia euclidiana, en donde la imagen viaja a través de un tiempo y espacio cronológico. Lo interesantemente original de la iniciativa de estas personas de Cauñikú, nos parece, fue precisamente usar la tele-visión mediática para poder difundir la tele-visión chamánica.

Uno de los productores de este video resulto ser profesor de chedungun de uno de los autores de este texto cuando este realizaba su investigación de terreno. En una de las lecciones, el profesor mostró este video en la televisión de su casa. Acá presentamos la propia traducción al castellano que este profesor hizo del video grabado en chedungun. La transcripción que sigue es la traducción literal que el profesor hacía a medida que distintas personas de la comunidad narraban lo que había sido pre-visto por los antiguos:

Hace muchísimo tiempo cuentan los ancianos, cuando nuestra gente antigua (kuiviche) aún escuchaba al gnenpin, al dueño de las palabras, a los antiguos, les fue revelado que un día nuestra sangre se mezclaría muchísimo con la sangre de otros. Nuestra gente antigua sabía lo que iba a pasar.

Ellos sabían que un gran remolino de viento (buta maulen) Ilegaría; muchas señales aparecerán cuando este momento llegue, y cuando este gran remolino llegue debemos cuidarnos mucho. ¡El remolino ya ha llegado!

Nuestra gente antigua ya había previsto que un camino sería construido a través de las comunidades, que aparecería un sendero para los caballos que cruzaría las montañas hasta donde el sol se levanta, y que en ese lugar levantarían una ciudad. Esto aún no ha ocurrido.

A través de un camino de dos sentidos, automóviles chilenos y argentinos viajarán, esto aún no ocurre, pero ocurrirá. Algún día, estas cosas sucederán, y cuando ustedes crezcan, podrán comprobarlo. Habrá señales, ustedes se darán cuenta. 
Desde la tierra, crecerá el oro. Ustedes verán abundancia en las montañas. Eso tomará tiempo. Muchas cosas llegarán, mucho trabajo.

Muchas cosas ajenas aparecerán. A cierto punto, Chile y Argentina estarán a punto de pelear, pero harán las paces. Habrá prosperidad, buena vida, trabajo. Pero, desde el cielo, un remolino gigante llegará, nuestros antepasados nos dijeron, y cuando el camino a traviese las montañas, por favor, tengan cuidado. Aconsejen a sus niños, fuerzas militares ocuparán el lugar, y aquellos que vivan cerca del camino sufrirán. No permanezcan cerca del camino.

Los winka tendrán una guerra entre ellos, se pelearan entre ellos. En esos días, nosotros necesitaremos nuestro antiguo modo de vivir, si es que lo olvidamos, sufriremos enormemente. Su friremos porque no seremos capaces de recolectar nuestra comida natural. No tendremos la comida que solíamos tener, katutu piedra, multrum, kollu kotun. Hoy en día todo lo que tenemos es pan winka. ¡Pero no durará por siempre! Por eso no debemos dejar de la do nuestra comida, nuestras siembras, aun cuando mucha de nuestra comida ya haya desaparecido, a pesar de las sugerencias de nuestros antepasados. El trigo centeno, la papa chira, muku, o uña de mula, todas esas comidas ya desaparecieron.

Por este motivo ustedes tienen que rezar a Chao, Chao Ngenechen, si es que quieren que él los reconsidere, si es que quieren que él les dé su sabiduría otra vez.

Ngenechen nos escucha en chedungun, ya que es esa la lengua que nos fue dada. Si ustedes hablan vuestra lengua, Ngenechen los mirará. Él les dará la comida, y si oramos, podremos saber dónde encontrar la comida. Por eso no podemos olvidar de dar siempre las gracias en nuestro nguillatun, por toda la comida que se nos ha dado, porque la comida tiene fuerza, la comida tiene newen ${ }^{11}$.

En esta profecía, hay elementos que quisiéramos desarrollar con mayor precisión, aún consientes que este ejercicio pueda implicar una miríada de equivocaciones y traiciones de traductor. Dentro de estos elementos, nos Ilama la atención la alusión a un "gran remolino de viento", en chedungun "buta maulen". Al preguntar a distintas personas del valle por el significado de esta entidad, nos fue dicho que un gran remolino de viento no es más que un enorme wekuve (entidad a la que nos referiremos más abajo) que trae varias cosas del exterior. Además, este wekuve viaja y se transporta a través del "camino", entidad que facilita y ordena la llegada de este y otras cosas desde el exterior. La llegada de este remolino de viento a través del camino, en el fondo, indica la llegada de una "nueva mentalidad", en donde la "mente" no es algo que pueda ser separado de los objetos.

Ahora detengámonos un momento en la idea que concibe al remolino como un gran wekuve. La palabra wekuve es usada en la vida cotidiana mapuche para
11 De manera muy interesante, esta profecía del valle del Queuko encuentra eco en una predicción del valle de Elicura, donde, como sabemos, el camino que se prevé en la primera profecía ya es un elemento más, constitutivo del lugar. Esta predicción, como la relataba literalmente un anciano de Elicura, en el contexto de un terremoto ocurrido en 2010 , era la siguiente: "La cultura mapuche, cuando se pierda, lo que dejaron dicho los antiguos es que se iba a terminar el mundo, iban a venir todas las ruinas... Cuando los Mapuche se terminen, cuando se transforme todo a winka ya, y nadie pueda hablar el chedungun y menos hacer una ceremonia, van a venir las grandes ruinas a la tierra... Hambre, recalentamiento de la tierra, el sol va a bajar a la tierra, van a venir grandes lluvias, así como de improvisto que se van a aparecer... Van a venir muchas enfermedades para la gente, y la tierra no va a dar mas su alimento.. Eso pronosticaron los antiguos, me acuerdo yo cuando era niño decían eso. Y en donde también decían los blancos se van a matar unos con otros porque van a pelear mucho por el capital, y así está ahora... Esos son los anuncios que hicieron ellos, también hablaban de grandes terremotos, hablaron de que el mar iba a terminar parte del mundo, inundando parte de la tierra, porque el mapuche se va a terminar, no va a existir mas". 
denominar a entidades con una intencionalidad subjetiva usualmente maligna (al menos, para los humanos). Etimológicamente, la palabra es una conjunción del término weku, que literalmente significa "afuera", y el sufijo ve, que se emplea para denotar al sujeto que realiza un acción determinada. Por lo tanto, wekuve podría ser traducido como "aquel que realiza el afuera". De manera interesante, en la terminología de parentesco mapuche, weku es el término para referir a $\mathrm{MoBr}^{12}$, el sujeto que tradicionalmente encarnaría la afinidad por excelencia, de acuerdo a la regla tradicional que prescribe el matrimonio con la prima cruzada matrilateral (ñukentun). Considerando previas descripciones de la persona mapuche como una entidad cuya composición se juega en el establecimiento de relaciones más allá de la filiación (Course, 2011; Conzález Cálvez, 2016), habría que decir que la relación que cada cual establece con su weku es un ejemplo paradigmático de las relaciones constitutivas de la persona, una constitución que está relacionalmente orientada hacia el exterior del núcleo tradicionalmente patrilineal. En la tradición antropológica, estas ideas resuenan con como Lévi-Strauss (1943) conceptualizó la relación con los extraños, en Sudamérica, a través de un modelo de relaciones entre afines; resuena también, más contemporáneamente, con la etnografía amerindia contemporánea y su afirmación de la cualidad constitutiva de la alteridad, en donde esta precede a la semejanza (Surrallés, 2000; Taylor y Viveiros de Castro, 2006; Viveiros de Castro, 2001).

A la luz de estas ideas, el considerar que el remolino de viento sea en realidad un gran wekuve implica pensar que todo aquello que lo constituye cuyo origen está afuera, soportado por la infraestructura del camino es un gran afín, con el cual se pueden establecer potencialmente relaciones personalmente constitutivas. Pero el relacionamiento con esta afinidad, que en este caso es casi una afinidad genérica o indistinguible a saber, un remolino de viento, está constituido por elementos materiales, por "cosas ajenas". Otra vez estamos en presencia de una constelación de la mente inmanente, en la que la relación de lo imaginario no puede desprenderse de la materialidad que lo origina. Dicho de otro modo, el exterior es inmanente; aun viniendo del externo, se identifica como un afín, un weku, alguien que habita en los confines y que llega por el camino construido mano a mano por chilenos y habitantes del valle. Es decir, el camino también cobra esa dimensión afuerina que aún al ser algo que viene del exterior, es previsto desde el interior, como algo inevitable.

Al mismo tiempo, la profecía articula normativamente un cierto tipo de infraestructura ambiental basada en una especie de antropología de lo indispensable, en la que la clave de la subsistencia radicaría en la mantención de un ensamblaje infraestructural constituido por las relaciones de mutualidad (alimentaria) entre personas y seres virtuales que hablan en la misma lengua. Como decía el productor del video profético, aquí, los más antiguos establecen
12 En ciertas zonas, según Faron (1961), weku es también el término utilizado para referir a todos los hombres de la familia de la madre, en una supuesta transición hacia una terminología omaha. 
que hay tres asuntos que es necesario no olvidar: la comida, la lengua, el ritual ("las rogativas" o "las ceremonias"). La profecía, así, y a través de las pantallas de la televisión moderna, aparece como la expresión de una infrareflexividad determinada por su estructura. Esta insistente determinación infraestructural de lo mapuche hace que el camino aparezca como un lugar que conecta las comunidades con las cosas ajenas y que, por ello, resulta ser un lugar progresivamente más transitado y peligroso, un lugar con la capacidad inmanente de exacerbar un contacto con el exterior que, como vimos, tiene el potencial de ser cada vez más auto-destructivo. Las relaciones sociomateriales que ofrece el camino, insospechadamente, regeneran la inconmensurabilidad de mundos diferentes en suspenso.

\section{ACTUALIZACIONES PELIGROSAS}

Tras años de intentos por recuperar sus territorios ancestrales, la comunidad Melimán de Elicura logró que el Estado chileno resarciera en parte la pérdida, entregándoles terrenos en un sector del valle llamado Ngol-Ngol, que formaron largo tiempo parte de una antigua estancia agrícola winka del lugar. Una vez entregados, y con mucha gente instalada en ellos, reapareció un problema que parecía parte del pasado: el acceso a estos terrenos era posible solo a través de una simple "huella", que ante la más mínima lluvia se desdibujaba y se volvía completamente intransitable. Aprovechando la cercanía que la directiva de la recién formada comunidad tenía con las compañías forestales del sector el presidente de la directiva era un antiguo obrero forestal y considerando que ya les habían donado una casa prefabricada, que funcionada como sede de reuniones, la comunidad inició una serie de conversaciones para solicitar apoyo de estas compañías para enripiar y mejorar la "huella", al menos hasta que el Estado procediera a transformarla en camino, asfaltándola definitivamente.

Esta situación radicalizó una escisión latente en la comunidad. Por una parte, estaban quienes intentaban sacar ventaja de la relación con las forestales; en general, estos eran los mismos que veían la presencia de estas positivamente, debido al trabajo que ellas proveían a parte importante de la población del lugar. Por otra, estaban quienes criticaban moralmente a las forestales, que veían su actuar hacia la gente dentro de la misma lógica maximizadora que empleaban en su relación con el resto de las entidades del valle. Ambas posiciones eran también interpretaciones de un nuevo trato forestal, entendido como un "fortalecimiento de relaciones comunitarias". Si bien existe un acuerdo general respecto a que las acciones enmarcadas en este paradigma tienen como finalidad facilitar las actividades realizadas por las compañías (Correa y Mella, 2010), hay quienes insisten en tomar partido de esta disposición, mientras otros 
presentan sus resquemores frente a los potenciales resultados de una vinculación con sus prácticas. Más allá de esta situación, las compañías realizaron las mejoras solicitadas que, además de servir a la gente de Ngol-Ngol, eran también útiles para el tránsito de sus propios camiones.

Tiempo después, en la misma línea de fortalecimiento de relaciones, la compañía comenzó a realizar un catastro de sitios "de interés cultural" que se encontraban dentro de predios forestales. Gracias al mejoramiento y extensión de la "huella"/camino de Ngol-Ngol, que se pierde en los cerros donde termina Elicura, se llegó al descubrimiento de un lugar llamado Yagyag, supuesto antiguo nguillatuwe (aprox. "lugar de rogativas"), ubicado a un costado de un salto de agua. Según se documentó, este lugar habría sido utilizado en rogativas colectivas e individuales para pedir por el bienestar general, por "bonanza" en años Iluviosos y para que haya lluvias en años de sequía. Muchos de quienes eran recelosos frente a las forestales encontraban extremadamente extraño que la compañía en cuestión pareciera tan dispuesta a devolver este sitio al control de las comunidades del valle, pues anteriormente ella se había mostrado reticente a entregar otros lugares que parecían mucho más importantes para la gente. Una respuesta al enigma que imponía este interés la entregó, al tiempo, una reconocida anciana del valle, en una reunión organizada por el servicio de salud provincial. Luego de enterarse de las intenciones que tenían "los de la forestal", en una conversación casual, ella relató:

En la cordillera hay un saltillo, dice el mapuche yagyag, un saltillo donde el agua cae de unos tres metros de alto... ipero no es na' nguillatuwe!, jahí habita el cherruve!... Hace unos ochenta años, noventa años puede ser, aquí abajo había una machi de Marilao que contaba... en ese tiempo, que no llovía, y fueron a hacer Ilover a esa parte (yagyag), y la machi fue con ellos... entonces después, cuando estaban allá, a la machi le dio el espíritu (entró en trance), y les dijo a todos que se fueran porque estaba el cherruve. ¡Salieron todos arrancando! Si no fuera por los ngenmapun (aprox. "dueños de la tierra"), los espíritus buenos que estaban, toda la gente, los que fueron con la machi, habrían muerto, porque el cherruve les iba a chupar la sangre... ¡Ese lugar no es nguillatuwe!, ¡si está el cherruve! ¿Quién va a ir a hacer nguillatun ahí? ¿Pa'ir a entregar la vida, pa' que el cherruve le chupe la sangre y lo mate? ¡No po!

El cherruve es descrito por la gente de Elicura como una entidad que se alimenta de la sangre de las personas ${ }^{13}$. En sentido estricto, es un wekuve que se alimenta de aquellos seres que transgreden su espacio vital. Es, análogamente, como el buta maulen de la profecía de Pitril. Sin embargo, si observamos con detención la situación que acabamos de describir, parece encontrarse un
13 Según Augusta, cherruve es un "fenómeno ígneo conocido con el nombre de 'bola de fuego"' (2007: 20-1). Montecino (2003) consigna una enorme cantidad de descripciones adicionales en esta misma línea. Para un análisis de la noción de sangre en relación con prácticas alimentarias, véase Bonelli (2014). 
paso delante de la línea profética que hemos desplegado en el acápite anterior. En este caso, es el nuevo camino, hecho ya desde una "nueva mentalidad" de maximización, el que permite la exacerbación de una relación con una entidad que, si no fuera por la existencia del mismo camino, no podría relacionarse con el valle de Elicura. Es, entonces, el camino que transgrede el espacio del cherruve y que lo conecta, desde su exterior, al valle, volviéndolo mediante esto interior a este. Estando ya cimentado y envuelto en la nueva mentalidad, la alteración que implica el camino no solo tiene que ver con la desaparición e invisibilización de ciertas entidades, sino, como sucedía con Ausangate en los Andes (De la Cadena, 2010), puede implicar un riesgo real a las vidas humanas. Todo por la exacerbación de la conexión o de lo que podríamos denominar un cierto tipo de "infrareflexividad predadora".

En conclusión, parece incuestionable asumir que los caminos conectan y desconectan distintos mundos sociomateriales. Las historias etnográficas de este trabajo muestran que existe un espacio de trasformación en el que se producen efectivamente transformaciones ontológicas a partir de eventos sociomateriales contingentes. La piedra de Pitril no es la misma después de la construcción del camino; los valles tampoco lo son, sin los seres que lo habitaban en el pasado. Pero, al mismo tiempo, el camino reconfigura distancias prohibidas, como el caso del cherruve de Elicura, cuya centralidad se desconfigura con la introducción del camino realizado por las forestales. Parece entonces evidente que, si bien las infraestructuras ambientales son múltiples, esa multiplicidad mantiene también una tensión infraestructural relacionada con infrareflexividades de por si inconmensurables.

\section{AGRADECIMIENTOS}

Nos gustaría agradecer a Salvador Schavelzon y al equipo editorial de Revista de Antropologia, por sus esfuerzos en la realización de este dossier. También extendemos nuestro reconocimiento a quienes evaluaron anónimamente este artículo en manera constructiva y a la vez desafiante. Este trabajo se realizó con el apoyo del Centro de Estudios Interculturales e Indígenas, CIIR (Conicyt/Fondap/15110006). Adicionalmente, uno de los autores pudo trabajar en este artículo gracias a los fondos de investigación Spinoza (Nwo) de la profesora Annemarie Mol, de la Universidad de Amsterdam. 
Cristóbal Bonelli es psicólogo clínico, terapeuta sistémico y doctor en antropología social. Actualmente trabaja como investigador post-doctoral Marie Curie en el instituto de educación en agua Unesco-IHE, y colabora con el Centro de Estudios Interculturales e Indígenas, clIR. Su investigación se interesa en la articulación sociomaterial entre comunicación, política y etnografía, al go que podría denominarse 'antropología clínica'.

Marcelo González Gálvez es profesor asistente del Programa de Antropología de la Pontificia Universidad Católica de Chile. Su investigación se centra sobre la relación/distinción entre persona y sociedad, y sobre la intersección de nociones como alteridad, socialidad, conocimiento y mundo.

\section{REFERÊNCIAS BIBLIOGRÁFICAS}

\section{ALLERTON, Catherine}

2013 Potent Landscapes: Place and Mobility in Eastern Indonesia.

Honolulu, University of Hawaii Press.

ANCÁN, José y CALFíO, Margarita

1999 "Retorno al país mapuche. Reflexiones en torno a una utopía por construir". Liwen, n. 5: 43-77.

AUCUSTA, Félix José

2007 [1916] Diccionario araucano. Santiago, Ediciones Cerro Manquehue.

AYLWIN, José; YAÑEZ, Nancy y SÁNCHEZ, Rubén

2013 Pueblo mapuche y recursos forestales en Chile: devastación y conservación en un contex to de globalización económica. Observatorio Ciudadano, Iwgia.

BASHKOW, Ira

2004 "A Neo-Boasian Conception of Cultural Boundaries". American Anthropologist, vol. 106, n. 3: 443-458.

BATESON, Gregory

1972 Steps to an Ecology of Mind. London, Jason Aronson Inc. 
BENGOA, José

2000 [1985] Historia del pueblo mapuche: siglo xIxy xx. Santiago, Lom.

BENNETT, Jane

2010 Vibrant Matter: A Political Ecology of Things. Durham, Duke University Press.

BOCCARA, Guillaume

2007 Los vencedores: historia del pueblo mapuche en la época colonial.

San Pedro de Atacama, Santiago, Línea Editorial IIAM-

Universidad Católica del Norte, Universidad de Chile.

BONELLI, Cristóbal

2012 "Ontological Disorders: Nightmares, Psychotropic Drugs and Evil

Spirits in Southern Chile". Anthropological Theory, vol. 12, n. 4: 407-426.

2014 "What Pehuenche Blood Does: Hemic Feasting, Intersubjective

Participation, and Witchcraft in Southern Chile". Hau:

Journal of Ethnographic Theory, vol. 4, n. 1: 105-127.

2015 "Eating One's Worlds: On Foods, Metabolic Writing and

Ethnographic Humour". Subjectivity, vol. 8, n. 3: 181-200.

BONELLI, Cristóbal y VICHERAT MATTAR, Daniela

En prensa "Towards a Sociology of Equivocal Connections". Sociology.

CORREA, Martín y MELLA, Eduardo

2010 Las razones del illkun/enojo: memoria, despojo y criminalización

en el territorio mapuche de Malleco. Santiago, Lom.

COURSE, Magnus

2011 Becoming Mapuche: Person and Ritual in Indigenous

Chile. Urbana, University of Illinois Press.

2012 "The Birth of the Word: Language, Force, and Mapuche Ritual

Authority". Hau: Journal of Ethnographic Theory, vol. 2, n. 1: 1-26.

2014 "The End of Me: The Role of Destiny in Mapuche Narratives

of the Person". In OAKDALE, S. y CourSE, M. (orgs.), Fluent Selves:

Autobiography, Person and History in Lowland South America.

Linconl, University of Nebraska Press, pp. 144-162.

DALAKOGLOU, Dimitris y HARVEY, Penny

2012 "Roads and Anthropology: Ethnographic Perspectivas on Space,

Time and (Im)mobility". Mobilities, vol. 7, n. 4: 459-465. 
DE LA CADENA, Marisol

2010 "Indigenous Cosmopolitics in the Andes: Conceptual Reflections beyond 'Politics'". Cultural Anthropology, vol. 25, n. 4: 334-70.

DELEUZE, Gilles y GUATTARI, Félix

1987 A Thousand Plateaus. Minneapolis, University of Minnesota Press.

DI GIMINIANI, Piergiorgio

2013 "The Contested Rewe: Sacred Sites, Misunderstandings and Ontological Pluralism in Mapuche Land Negotiations". Journal of the Royal Anthropological Institute, vol. 19, n. 3: 527-544.

2015 "The Becoming of Ancestral Land: Place and Property in Mapuche Land Claims". American Ethnologist, vol. 42, n. 3: 490-503.

FARON, Louis

1961 "The Dakota-Omaha Continuum in Mapuche Society". Journal of the Royal Anthropological Institute, vol. 91, n. 1: 11-22.

FERNÁNDEZ, César (org.)

1999 Cuentan los mapuches. Buenos Aires, Editorial Nuevo Siglo.

FOERSTER, Rolf

2004 ¿Pactos de sumisión o actos de rebelión? Una aproximación histórica y antropológica a los mapuches de la costa de Arauco, Chile. Leiden, tese, Universiteit Leiden.

FOERSTER, Rolfy MENARD, André

2009 "Futatrokikelu: Don y autoridad en la relación mapuche-wingka". Atenea, n. 499: 33-59.

GONZÁLEZ, Héctor

1986 "Propiedad comunitaria o individual. Las tierras indígenas y el pueblo mapuche". Nütram, vol. 2, n. 3: 7-13.

GONZÁLEZ GÁLVEZ, Marcelo

2015 "The Truth of Experience and Its Communication: Reflections on Mapuche Epistemology". Anthropological Theory, vol. 15, n. 2: 141-157.

2016 Los mapuchey sus otros: persona, alteridad y sociedad en el surde Chile. Santiago, Editorial Universitaria. 
GÜNDERMANN, Hans; CANIHUAN, Jacqueline;

CASTILLO, Ernesto y CLAVERÍA, Alejandro

2008 Perfil sociolingüístico de comunidades mapuches de la VIII, IX yX

Región. Santiago, Universidad Tecnológica Metropolitana.

HENARE, Amiria; HOLBRAAD, Martin y WASTELL, Sari

2007 Thinking through Things: Theorising Artifacts

Ethnographically. London, Routledge.

HENNION, Antoine y GRENIER, Line

2000 "Sociology of Art: New Stakes in a Post-Critical Time".

In QuAH, S. R. y SALES, A. (orgs.), The International

Handbook of Sociology. London, Sage, pp. 341-355.

HOLBRAAD, Martin; PEDERSEN, Morten y VIVEIROS DE CASTRO, Eduardo

2014 "The Politics of Ontology: Anthropological Positions".

Theorizing the contemporary, Cultural Anthropology website, January 13, 2014. https://culanth.org/fieldsights/462-thepolitics-of-ontology-anthropological-positions.

JENSEN, Casper Brunn

2015 "Experimenting with Political Materials: Environmental Infraestructuras and Ontological Transformations".

Distinktion: Scandinavian Journal of Social Theory 1-14.

2016 "Pipe Dreams: Sewage Infrastructures and Activity

Trails in Phnom Penh". Ethnos 1-21.

KOESSLER-ILG, Berta

2007 Cuenta el pueblo mapuche. Santiago, Mare Nostrum.

KOHN, Eduardo

2013 How Forest Think: Toward an Anthropology beyond the Human. Berkeley, University of California Press.

LARKIN, Brian

2013 "The Politics and Poetics of Infrastructure". Annual Review of Anthropology, vol. 42: 327-343. 


\section{LATOUR, Bruno}

1988 "The Politics of Explanation: An Alternative". In WOOLGAR, S. (org.), Knowledge and Reflexivity. London, Sage, pp. 155-177.

LEA, Tess y PHOLEROS, Paul

2010 "This is not a Pipe: The Treacheries of Indigenous

Housing". Public Culture, vol. 22, n. 1: 187-209.

LÉVI-STRAUSS, Claude

1943 "The Social Use of Kinship Terms among Brazilian Indians".

American Anthropologist, vol. 45, n. 3: 398-409.

MATURANA, Humberto y VARELA, Francisco

1984 El árbol del conocimiento: las bases biológicas del entendimiento humano. Santiago, Editorial Universitaria.

MEINERT, Lotte y KAPFERER, Bruce

2015 In the Event: Toward an Anthropology of Ceneric

Moments. London, Berghahn.

MILLALÉN, José

2006 "La sociedad mapuche prehispánica: Kimün, arqueología y etnohistoria". In MARIMAN, P, et al (orgs.), $; \ldots$

Escucha, winka...!. . Santiago, Lom, pp. 17-52.

MONTECINO, Sonia

2003 Mitos de Chile: diccionario de seres, magiasy encantos. Santiago, Sudamericana.

NADASDY, Paul

2007 "The Gift in the Animal: The Ontology of Hunting and HumanAnimal Sociality". American Ethnologist, vol. 34, n. 1: 25-43.

PEDERSEN, Morten y BUNKENBORG, Mikkel

2012 "Roads that Separate: Sino-Mongolian Relations in the Inner Asian Desert". Mobilities, vol. 7, n. 4: 555-569.

POVINELLI, Elizabeth

1995 "Do Rocks Listen? The Cultural Politics of Apprehending Australian Aboriginal Labor". American Anthropologist, vol. 97, n. 3: 505-518. 
2001 "Radical Worlds: The Anthropology of Incommensurability and Inconceivability". Annual Review of Anthropology, vol. 30: 319-334.

RANCIĖRE, Jacques

2006 Política, policía, democracia. Santiago, Lom.

SCHINDLER, Helmuth y SCHINDLER-YÁÑEZ, Minerva

2006 "La piedra santa del río Lumaco". In SCHINDLER, H. (org.),

Acerca de la espiritualidad mapuche. München, Martin

Meidenbauer Verlagsbuchhandlung, pp. 11-67.

STRATHERN, Marilyn

1992 After Nature: English Kinship in the Late Twentieth Century.

Cambridge, Cambridge University Press.

SURRALLÉS, Alexandre

2000 "La Passion génératrice. Prédation, échange et redoublement du mariage candoshi". L'Homme, vol. 154: 123-144.

TAYLOR, Anne-Christine y VIVEIROS DE CASTRO, Eduardo

2006 "Un Corps fait de regards". In BRETON, S. (org.), Qu'est-

ce qu'un Corps? Paris, Musée du Quai Branly.

TEILLIER, Fernando

2013 "Vitalidad lingüística del chedungun en Chile y epistemología del hablante". Revista de Lingüística Teoríca y Aplicada, vol. 51, n. 1: 53-70

VIVEIROS DE CASTRO, Eduardo

2001 "Gut Feelings about Amazonia: Potential Affinity and the Construction of Sociality". In RIVAL, L. y WHITEHEAD, N. (orgs.), Beyond the Visible and the Material: The Amerindianization of Society in the Work of Peter Riviere. Oxford, Oxford University Press, pp. 19-43.

2004 "Perspectival Anthropology and the Method of Controlled Equivocation". Tipiti: Journal of the Society for the Anthropology of Lowland South America, vol. 2, n. 1: 3-22. 


\section{What Does a Road Do? Infrastructural Alterations in Southern Chile}

\section{ABSTRACT}

In this article we offer an account of the socio-material transformation that has triggered the building of roads in the indigenous worlds in southern Chile. Taking our starting point from Bateson's theory of the "immanent mind", we attempt to comprehend and conceptualize the capacities of roads to reconstitute radically a relationally constituted world, a world that is therefore in itself contingent. By means of our ethnographic explorations, we propose that the road does not make alterations possible simply by promoting contact, interconnections, and intercultural relations, but also by altering the world materially, promoting "inter-socio-material" relations determined infrastructurally. Finally, we suggest that the material alteration of the world produces uncertain results, including possibly its own destruction. In this sense, this article discusses ethnographically the problem of ontological selfdetermination in infrastructural terms.

Recebido em novembro de 2015. Aceito em setembro de 2016.

\section{KEYWORDS}

Roads, Infrastructure, Mapuche, Immanent Mind, Ontological Alterations 